\title{
O DIÁLOGO COMO FERRAMENTA METODOLÓGICA NA FORMAÇÃO DE JOVENS AMBIENTALISTAS: O CASO DO COLETIVO JOVEM ALBATROZ ${ }^{1}$
}

\author{
Thaís Cândido Lopes ${ }^{2}$ \\ Rafael de Araujo Arosa Monteiro ${ }^{3}$
}

Resumo: A prática pedagógica "bancária" reforça valores como a competição, o individualismo, a dominação, entre outros, gerando uma postura impositiva e autoritária nos educadores. Por outro lado, a prática do diálogo como ferramenta pedagógica é um meio de garantir a autonomia e a emancipação das pessoas envolvidas no processo educativo. Neste sentido, para enfrentar os problemas socioambientais, a Educação Ambiental de base dialógica apresenta-se como um caminho possível para a transformação. Dessa forma, o presente artigo buscou contribuir para o aprofundamento dos conhecimentos de diálogo na formação de jovens ambientalistas a partir da análise dos processos de formação desenvolvidos dentro do Coletivo Jovem Albatroz (CJA) durante os anos de 2015 a 2019. Para isso, adotou-se como metodologia uma abordagem qualitativa, analisando diversos documentos (relatórios de monitoramento e relatos de experiência) a partir de três categorias: construção de um ambiente dialógico; liderança dialógica; e aprendizado do diálogo. Foi possível identificar, nos processos educadores do CJA, o fomento da construção de um ambiente dialógico por uma liderança que se dispõe a ser dialógica, o que contribuiu para o aprendizado e vivência do diálogo. Em paralelo, também foram encontrados desafios para a manutenção de tal dialogicidade, como a dificuldade dos jovens se manterem no Coletivo e a aproximação de novos jovens provenientes de áreas do conhecimento distintas da área ambiental.

Palavras-chave: Diálogo; Educação Ambiental; Juventude; Coletivos Jovens de Meio Ambiente.

\footnotetext{
$1 \mathrm{O}$ artigo é fruto da monografia de conclusão de curso desenvolvida pela primeira autora, sob orientação do segundo autor, junto ao Curso de Especialização em Educação Ambiental e

Transição para Sociedades Sustentáveis da ESALQ-USP.

2 Coordenadora do Coletivo Jovem Albatroz. E-mail: thaislopes.ma@gmail.com.

Link para o Lattes: http://lattes.cnpq.br/2363551362679750

${ }^{3}$ Doutorando e Mestre em Ciências pela Universidade de São Paulo (PROCAM - USP).

E-mail: rafael.araujo.monteiro@usp.br. Link para o Lattes: http://lattes.cnpq.br/5585638635194187
} 
Abstract: The "banking" pedagogical practice reinforces values such as competition, individualism, domination, among others, generating an imposing and authoritarian posture in educators. On the other hand, the practice of dialogue as a pedagogical tool is a way to ensure the autonomy and emancipation of the people involved in the educational process. In this sense, in order to face socioenvironmental problems, dialogical-based environmental education presents itself as a possible path to transformation. Thus, the present article sought to contribute to the deepening of the knowledge of dialogue in the training of young environmentalists based on the analysis of the training processes developed within the Young Albatross Collective (CJA) during the years 2015 to 2019. For this, a qualitative approach was adopted as methodology, analyzing various documents (monitoring reports and experience reports) from three categories: building a dialogic environment; dialogic leadership; and learning from dialogue. It was possible to identify, in the educative processes of the CJA, the fostering of the construction of a dialogic environment by a leadership that is willing to be dialogic, which contributed to the learning and posture in educators. On the other hand, the practice of dialogue as a pedagogical tool is a way to ensure the autonomy and emancipation of the people involved in the educational process. In this sense, in order to face socio-environmental problems, dialogical-based environmental education presents itself as a possible path to transformation.

Keyword: Dialogue; Environmental Education; Youth; Young Environmental Collective.

\section{Introdução}

Os problemas socioambientais enfrentados atualmente pela sociedade moderna ocidental estão diretamente ligados aos valores da tríade ciênciaimperialismo-capitalismo, sendo eles: a fragmentação da realidade, a competição excessiva, o individualismo exacerbado, a busca incessante pelo lucro econômico, a dominação do outro, entre outros (JACOBI; MONTEIRO; SORRENTINO, 2020; LOPES et al., 2020).

Tais valores são incorporados pelas pessoas ao longo de suas vidas, sendo transmitidos e perpetuados, muitas vezes, por uma educação "bancária", como sugeriu Freire (1981). O educador é o detentor do conhecimento e precisa "depositá-lo" nos educandos (alusão ao depósito de uma quantia de dinheiro em contas de banco), como se suas cabeças fossem recipientes vazios (FREIRE, 1981), assumindo uma postura impositiva e autoritária. Dessa forma, os educandos ficam impedidos de questionar e criticar as ideias e valores vigentes.

Sendo assim, se a sociedade almeja enfrentar os problemas socioambientais, é necessário a implementação de práticas educadoras que superem a prática "bancária", buscando garantir a autonomia e a emancipação das pessoas (ANDRADE; LUCA; SORRENTINO, 2012).

Um caminho promissor para tal enfrentamento é por meio de uma Educação Ambiental (EA) que estimule 0 aprendizado do diálogo, 
caracterizado como uma forma de se comunicar com o outro que possibilita que as pessoas pensem em conjunto, permitindo o surgimento de novas compreensões sobre 0 modo que pensamos e agimos diariamente (MONTEIRO; SORRENTINO, 2019). A partir dessa prática dialógica é possível promover a interação entre pessoas ou grupos, sem descaracterizar ou anular a essência e as especificidades de cada um, isso ocorre porque o diálogo é capaz de diminuir barreiras culturais e cognitivas, conciliando contradições inerentes à vida (ALVES et al., 2010).

O Tratado de Educação Ambiental para Sociedades Sustentáveis e Responsabilidade Global (FÓRUM GLOBAL DAS ONGs, 1992) corrobora a necessidade de uma EA que investigue os problemas estruturais da sociedade atual, modelo que apresenta falhas e crises que afetam todas as formas de vida no planeta. $\mathrm{E}$, ainda, propõe o diálogo enquanto um caminho a ser trilhado para a construção e concretização de novos valores na transição para uma sociedade socialmente justa e ecologicamente equilibrada, com relações interdependentes e diversas. Tal proposta é apresentada também em outros documentos nacionais como o Programa Nacional de Educação Ambiental [ProNEA] (BRASIL, 2018) e o Programa de Formação de Educadores(as) Ambientais [ProFEA]) (ÓRGÃO GESTOR DA PNEA, 2006).

Nesse sentido, Sorrentino et al. (2013, p. 37) afirmam que estimular o diálogo constitui um desafio e uma necessidade para a realização de uma EA "que fortalece e confere autonomia e confiança aos indivíduos, que promove a coexistência equilibrada entre as realidades e contextos pessoais e coletivos, entre o moderno e as tradições, entre a tecnologia e o jeito simples de ser".

De acordo com diversos estudos (ANDRADE, 2013; AVANZI, 2005; LUCA; ANDRADE, 2013; ROESE, 2014; SILVA, 2016; MONTEIRO; SORRENTINO, 2019), é possível perceber que, à medida em que se formam ambientalistas comprometidos com a transição para sociedades sustentáveis, a vivência e o aprendizado do diálogo apresentam-se como aspectos de grande relevância.

Todavia, um dos principais desafios apontados por Andrade e Sorrentino (2014) no texto de Monteiro e Sorrentino (2019, p. 12) para uma EA dialógica

é a elaboração e implementação de pedagogias dialógicas em contextos formais e não formais de educação, de forma que os educadores devem estar sempre se questionando sobre sua prática à luz da concepção dialógica.

Para isso, é de grande relevância a investigação de casos de Educação Ambiental que incorporem, em suas ações, o estímulo ao aprendizado da prática dialógica. Dessa maneira, o presente estudo buscou contribuir para o aprofundamento de conhecimentos sobre o diálogo na formação de jovens ambientalistas a partir da análise da ocorrência do diálogo dentro do Coletivo Jovem Albatroz (CJA), um espaço de formação de jovens ambientalistas que 
adota, em sua prática, a Educação Ambiental dialógica, a partir dos processos de formação desenvolvidos.

\section{O Coletivo Jovem Albatroz e os Processos Participativos}

O Coletivo Jovem Albatroz (CJA) é uma frente de atuação do Projeto Albatroz, organização não governamental voltada à conservação de albatrozes e petréis, aves marinhas migratórias ameaçadas de extinção por conta de sua interação com a pescaria de espinhel (PROJETO ALBATROZ, 2020a).

Tal coletivo se constitui enquanto um espaço de formação de jovens entre 18 e 29 anos de idade, residentes na Baixada Santista. Foi fundado em agosto de 2015 com o intuito de fortalecer o protagonismo juvenil e fomentar ações conjuntas entre os Projetos Albatroz, Baleia Jubarte, Coral Vivo, Golfinho Rotador e Tamar (PROJETO ALBATROZ, 2020b), todos patrocinados pelo Programa Petrobras Socioambiental e integrantes da Rede BIOMAR (REDE BIOMAR, 2016). Atualmente, estão entre seus propósitos a formação de jovens lideranças para atuar na transição para sociedades sustentáveis, a conservação de ambientes costeiros e marinhos e o fomento às interrelações entre os diversos atores existentes nesses contextos (PROJETO ALBATROZ, 2020a).

Tais objetivos estão embasados na concepção de Educação Ambiental do Laboratório de Educação e Política Ambiental - Oca da Universidade de São Paulo (USP), caracterizada por cinco pilares - identidade, comunidade, diálogo, potência de ação e felicidade (SORRENTINO et al., 2005); no "Método" Oca, caracterizado por uma estrutura dialógica-incremental, portanto sem fórmula fixa (OCA, 2016); e pelos três princípios orientadores de Coletivos Jovens de Meio Ambiente do Brasil: jovem educa jovem, jovem escolhe jovem e uma geração aprende com a outra (BRASIL, 2005).

\section{Diálogo como Referencial Teórico}

O presente estudo adotou, como referencial teórico, a síntese das características e princípios do diálogo na visão de David Bohm, William Isaacs e Paulo Freire, elaborada por Monteiro e Sorrentino (2019), a qual propõe duas categorias de perguntas-indicadoras, cuja finalidade é subsidiar o desenvolvimento, execução e avaliação dos processos de Educação Ambiental de base dialógica.

Essas perguntas-indicadoras foram reformuladas por Monteiro e Ribeiro (2020) em três novas categorias: liderança dialógica e construção de um ambiente dialógico; condições físicas para emergência do diálogo; e aprendizado do diálogo. Na categoria aprendizado do diálogo, vale ressaltar a existência de um procedimento metodológico, sugerido por Monteiro e Sorrentino (2019), que estimula o aprendizado e a vivência do diálogo.

Tal procedimento se caracteriza por um processo composto de quatro momentos: "(1) codificação; (2) observação da codificação ou escuta genuína; 
(3) descrição da codificação; (4) "re-admiração" das admirações, observando as sensações corporais e emoções e analisando criticamente todo o processo" (MONTEIRO; SORRENTINO, 2019, p. 18).

A codificação caracteriza-se pela representação de algum aspecto da realidade, que pode se dar por meio da fala de outras pessoas ou por imagens, por exemplo. Conforme a informação é recebida, as pessoas podem realizar a observação da codificação ou escuta genuína, focando sua atenção para identificar as emoções e sentimentos que surgem ao recebê-las em silêncio. Em seguida, no terceiro momento, o de descrição da codificação, as pessoas compartilham os pensamentos, as sensações, os sentimentos e as dúvidas sobre aquilo que se está conversando. Então, segue-se para o último momento proposto pelos autores, um convite para (re)admirar as admirações, observando as sensações corporais e emoções e analisando criticamente todo o processo, ou seja, é o momento em que se busca compreender a maneira que se pensa e age a partir de um novo olhar para as suas verdades e as verdades do outro (MONTEIRO; SORRENTINO, 2019).

As categorias de análise e as perguntas-indicadoras do diálogo construídas por Monteiro e Ribeiro (2020) foram apropriadas e adaptadas para subsidiar as análises deste artigo, conforme apresentado na Quadro 1:

Quadro 1: Categorias de análise e perguntas-indicadoras do diálogo.

\begin{tabular}{|c|l|}
\hline CATEGORIAS & \multicolumn{1}{|c|}{ PERGUNTAS-INDICADORAS } \\
\hline \multirow{5}{*}{$\begin{array}{c}\text { Construção de um } \\
\text { ambiente dialógico }\end{array}$} & $\begin{array}{l}\text { Há indícios da presença do amor, da humildade, da fé, da confiança, } \\
\text { da esperança e do pensar crítico no processo vivido, como proposto } \\
\text { por Freire (1981)? }\end{array}$ \\
\cline { 2 - 3 } Liderança dialógica & $\begin{array}{l}\text { Todos podem se expressar, respeitando e ouvindo, por sua vez, os } \\
\text { outros? }\end{array}$ \\
\hline \multirow{5}{*}{ Aprendizado do diálogo } & $\begin{array}{l}\text { A liderança participa como integrante do diálogo, realizando o } \\
\text { mesmo exercício que todos os envolvidos? }\end{array}$ \\
\cline { 2 - 3 } & $\begin{array}{l}\text { A liderança fomenta a construção de um ambiente seguro e de } \\
\text { confiança? }\end{array}$ \\
\hline & $\begin{array}{l}\text { Há indícios do aprendizado do procedimento metodológico proposto } \\
\text { por Monteiro e Sorrentino (2019)? }\end{array}$ \\
\cline { 2 - 2 } & $\begin{array}{l}\text { Há do aprendizado sobre si, sobre o outro e/ou sobre algum } \\
\text { diálogo (procedimento metodológico)? }\end{array}$ \\
\hline
\end{tabular}

Fonte: Elaborado pelos autores e adaptado de Monteiro e Ribeiro (2020). 


\section{Caminho Metodológico}

A fim de alcançar o objetivo proposto, o presente estudo adotou uma abordagem qualitativa, que possui como característica dados e análise descritiva, não quantificáveis e indutivas (LUDKE; ANDRÉ, 1986). Como inspiração metodológica, optou-se pelo estudo de caso, cujo princípio base é a investigação de um caso específico, bem delimitado, para que se possa adquirir conhecimentos a respeito de uma temática estudada (LUDKE; ANDRÉ, 1986).

O período temporal considerado compreendeu os anos de 2015 a 2019, abarcando seis processos formativos realizados pelo Coletivo Jovem Albatroz neste intervalo de tempo, sendo eles os cursos de: Formação de Lideranças Jovens em Políticas Públicas de Conservação Marinha; Educação Ambiental e a Transição Educadora Ambientalista para Sociedades Sustentáveis; Educomunicação e Processos de Educação Ambiental em ambientes costeiros e marinhos; Produção Audiovisual - Uma Ferramenta Educomunicativa para Processos de Educação Ambiental em Conservação Marinha; Oficina de Elaboração de Projetos Ambientais e Culturais; e o Planejamento Participativo do III Encontro Nacional Jovem Mar (III EJM). Todos eles apresentam, como principal característica, os jovens como protagonistas do processo educador (PROJETO ALBATROZ, 2020b).

Para a coleta dos dados, foram utilizadas informações dos relatórios de atividades da gerência de Educação Ambiental do Projeto Albatroz, de publicações científicas relacionadas ao CJA e das mídias sociais (redes sociais e site) do Projeto Albatroz. Além disso, todos os 91 jovens que passaram pelo CJA ao longo desse período receberam, via e-mail, um convite para contribuir com esta pesquisa por meio da escrita de relatos de experiência. Desse total, retornaram 18 relatos de jovens de momentos de formação distintos do CJA.

Os dados foram analisados por meio da análise de documentos (LUDKE; ANDRÉ, 1986), considerando o processo formativo efetuado pelo Coletivo Jovem Albatroz de maneira geral, ou seja, os cursos foram agrupados como um grande processo formativo e analisados como tal, ao invés de fazê-lo separadamente.

Além disso, a análise consistiu na identificação de frases ou parágrafos, presentes nos documentos, em busca de indícios dos aspectos do diálogo com base no quadro analítico, construído a partir da adaptação das três categorias de análise propostas por Monteiro e Ribeiro (2020) (Quadro 1). Uma primeira análise foi feita com o intuito de organizar e separar os dados de acordo com as categorias estabelecidas. Em seguida, foi realizada uma segunda leitura buscando interpretar os dados encontrados à luz das categorias. A seguir são apresentados os resultados e respectivas discussões. 


\section{Análise dos Resultados à Luz do Diálogo}

A seguir, são apresentadas as análises realizadas a partir das perguntas-indicadoras do diálogo, constituintes das três categorias propostas: construção de um ambiente dialógico, liderança dialógica e o aprendizado do diálogo.

\section{Construção de um ambiente dialógico}

A partir da análise documental, foi possível encontrar elementos que dão indícios do fomento de um ambiente propício para a emergência do diálogo (MONTEIRO; SORRENTINO, 2019).

De acordo com Paulo Freire (1981) o amor, a fé, a confiança, a humildade, a esperança e o pensamento crítico são características essenciais para a criação desse campo de conversação.

Para Freire (1981), o amor é interpretado como um atributo que permite conexão e acolhimento entre os seres, gerando o desejo de que todos possam se desenvolver, coletivamente e individualmente. Nesse sentido, foi possível encontrar indícios do estímulo desse amor freireano na realização de refeições coletivas, como evidenciado na primeira formação realizada pelo CJA (PROJETO ALBATROZ, 2015), fomentando a socialização, integração e construção de vínculos entre os jovens. Tal estímulo também apareceu no depoimento escrito do Jovem 1, ao afirmar que o CJA "estimula constantemente 0 agir coletivamente, respeitando os diversos corpos e pensamentos existentes". Disse ainda ser constantemente estimulado em seu processo de desenvolvimento, ao afirmar "[...] estar o tempo todo me reeducando, me colocando em análise e às vezes até em conflito com o cotidiano".

A característica da fé relaciona-se com o ato de acreditar no potencial de todos os seres humanos para se desenvolver e transformar sua realidade, aspecto que deve ser nutrido antes mesmo que o diálogo se instale dentro do grupo (FREIRE, 1981). O Jovem 10 refere-se a essa característica ao relatar uma atividade realizada pelo CJA:

[Era uma ação] com as crianças que frequentam o Arte no Dique, no Dique da Vila Gilda, Zona Noroeste em Santos. O ambiente era lindo [...] com um quadro bem grande no espaço central com o trecho de uma das canções de Gilberto Gil: "Andá com fé eu vou, que a fé não costuma faiar". Nesse dia minha fé só aumentou. Fé nos pequenos que passaram o dia conosco. Fé em acreditar que nosso trabalho com Educação Ambiental faz diferença na vida do próximo. 
Além disso, o Jovem 7 relatou sua experiência durante os primeiros encontros da sua primeira formação dentro do Coletivo, dizendo que "senti que passaria vergonha, mas resolvi ir ao primeiro encontro e saber melhor com 0 que eu estava lidando". Essa fala parece demonstrar um receio do jovem ao ingressar em um novo ambiente. Complementa enunciando a superação desse medo ao dizer que "no primeiro encontro vi no rosto dos meus futuros colegas a mesma expressão que provavelmente eu carregava em meu rosto [...]. Pensei 'ao menos eu não estou sozinha nessa'. Percebi, cada vez mais, que uma coisa que eu não estava era sozinha". Em seu relato, é possível identificar indícios de segurança e identificação que fomentam a característica da confiança.

A esperança, por sua vez, representa o propósito do diálogo, ou seja, sugere que o processo educador deve ter um objetivo a ser atingido (FREIRE, 1981). Essa característica parece ficar clara na fala do Jovem 2, que participou da primeira formação no ano de 2015, quando afirma que "o foco [da formação] era deixar um impacto positivo na comunidade local e construir uma estrutura juntos que pudesse contribuir em um futuro próximo para outros jovens". Em adição, o Jovem 9 reforça essa intencionalidade ao escrever que o CJA "representa um espaço onde jovens podem criar suas iniciativas, de forma autônoma e democrática internamente". Tais depoimentos parecem indicar a materialização da intencionalidade dos educadores responsáveis em fomentar um espaço de construção coletiva e dialógica (PROJETO ALBATROZ, 2020c) de utopias e intervenções (OCA, 2016).

O pensar crítico, caracterizado por uma análise do contexto históricocultural (FREIRE, 1981), foi identificado no relato do Jovem 1, ao dizer que "a cada encontro conseguimos crescer pessoalmente um pouco mais. Nos desconstruir dentro dos sistemas que foram impostos pelas gerações anteriores, produzindo potencialmente os nossos saberes e os nossos próprios sistemas".

Ademais, indício do estímulo à humildade foi encontrado na forma como foram organizados os Encontros Jovem Mar (primeira, segunda e terceira edição), promovidos pelos projetos da Rede Biomar, e o Encontro Jovem Transformar (primeira edição), promovido pelo Projeto Tamar. Esses eventos fomentaram o encontro entre coletivos, com jovens de outras culturas e realidades, estimulando, por meio das atividades propostas e tempo de socialização, a possibilidade de ouvir e conversar com o diferente, exercitando a humildade ao promover trocas de saberes, sem a necessidade de impor ou julgar a maneira de interpretar o mundo do outro (FREIRE, 1981).

Outros elementos fundamentais para a criação de um ambiente dialógico, descritos por Monteiro e Sorrentino (2019), são a expressão, o respeito e a escuta.

O Jovem 2 relata as dificuldades iniciais que o grupo teve em estabelecer uma maneira colaborativa de se relacionar durante a primeira 
formação do CJA: "não foram poucas as vezes que nós do coletivo passamos por situações de conflito de ideias". No entanto, complementa dizendo que "nos organizamos em uma estrutura onde todos possuíam voz [...] lidar diretamente com pessoas deixou de ser um desafio e passou a se tornar um prazer em minha vida, e isso reflete em toda minha formação e atuação nos dias de hoje". Essa fala parece indicar a presença de um ambiente fomentador do diálogo, isto porque evidencia a liberdade que os jovens sentiam para se expressar livremente, lidando com os conflitos de ideias (MONTEIRO; SORRENTINO, 2019).

Outra evidência importante da valorização dessas características apareceu no Relatório CJA - Evidência de realização das ações (PROJETO ALBATROZ, 2016) ao relatar a abertura da coordenação geral e de Educação Ambiental do PA em ouvir as demandas dos jovens no processo de construção do projeto para renovação de contrato com o patrocinador.

O Jovem 10 reforçou, ainda, a intenção do educador responsável pelo CJA em valorizar a construção coletiva, incentivando a expressão de cada integrante do grupo. Em complemento, o Jovem 17 afirmou: "é um espaço onde ideias podem ser expostas e dialogadas, mudar nossa perspectiva sobre vários assuntos, além de oportunizar momentos incríveis [...] dando voz a nós jovens que muitas vezes não são levados em consideração".

Vale ressaltar também que a coordenação geral e de EA do PA, ao acreditar na importância do protagonismo juvenil, deu uma verdadeira prova de coerência entre seu discurso e prática ao permitir que os jovens ficassem à frente da construção, realização e execução do III EJM. Para viabilizar esse processo, o educador do PA assumiu a função de orientador e não de dono do processo, indício importante de uma liderança que se pretende dialógica para a construção desse ambiente (MONTEIRO et al., 2018).

Para além das características internas ou emocionais já expostas, o estabelecimento de um campo de conversação com qualidade dialógica depende de condições físicas para existir, como a disposição circular das cadeiras na sala, um local com uma boa acústica, a frequência dos encontros e o número de participantes (MONTEIRO; SORRENTINO, 2019).

As formações realizadas pelo CJA apresentavam aspectos físicos semelhantes por ocorrerem, em sua maioria, no mesmo local. Este possuía uma boa acústica, onde os jovens podiam se comunicar sem grandes dificuldades (MONTEIRO; SORRENTINO, 2019).

A disposição dos jovens na sala de aprendizado foi estabelecida por um combinado coletivo, que se manteve ao longo de todas as formações, no qual se definiu manter o formato de uma roda, onde todos conseguissem se enxergar (PROJETO ALBATROZ, 2015). Tal disposição física é apresentada por Monteiro e Sorrentino (2019, p. 17) como um aspecto externo para o fomento de um ambiente dialógico, "uma vez que tal arranjo não gera privilégios" e mantém a horizontalidade entre os jovens. 
No que diz respeito à frequência dos encontros, a análise documental apontou que a maioria das formações realizadas pelo CJA não seguia o sugerido por Bohm (2005 apud MONTEIRO; SORRENTINO, 2019). Os autores sugerem um encontro por semana ou um a cada quinze dias, já o CJA, em sua maior parte do tempo, realizava encontros durante dois dias na mesma semana. Apesar disso, é possível inferir que tal frequência não afetou o diálogo, pelo contrário, estimulou um convívio mais constante, facilitando a confiança entre os jovens.

Já em relação ao número de participantes, cada formação contou com uma quantidade específica de jovens, visto que cada uma adotou uma metodologia diferente. As formações que divergiam do número sugerido por Monteiro e Sorrentino (2019), entre 20 e 40 participantes, contaram com um número abaixo do proposto, mas esse fator não limitou o aprendizado e a vivência do diálogo, isso porque a quantidade de participantes menor do que o indicado parece ter favorecido as trocas e a criação de laços afetivos entre o grupo.

Tendo em vista o exposto até aqui, é possível afirmar que a coordenação de Educação Ambiental do PA, educadores responsáveis e jovens nutriram um ambiente dialógico ao darem espaço para a expressão, respeito e escuta, sentindo-se seguros para se expor aos outros, pensando e refletindo juntos sobre aspectos da vida. Além disso, conseguiram estabelecer um campo de conversação com qualidade dialógica ao buscarem adaptar as condições externas para emergência do diálogo, como a frequência semanal dos encontros, a busca por encontros onde a disposição das cadeiras fosse circular, o número de jovens, entre outros expostos acima.

Ainda vale destacar que foi possível encontrar desafios relacionados com a construção desse ambiente dialógico.

O Jovem 18 relata que "mesmo admirando muito o Projeto e o papel do Coletivo, sempre achei que era um grupo restrito aos estudantes de biologia ou cursos correlatos". A impressão inicial desse jovem fez emergir nele a compreensão de que o CJA era restrito a tal público. No entanto, o Coletivo tem a intenção contrária, ou seja, busca agregar jovens de diferentes áreas do saber. Ao ingressar no grupo, o Jovem 18 percebeu tal intencionalidade. Contudo, levanta-se, aqui, um aspecto importante de ser reconhecido e refletido pelo CJA, já que outros jovens podem ter a mesma impressão e, por isso, acabar deixando de aproximar-se do Coletivo.

Dessa forma, o CJA parece defrontar-se com uma possível incoerência: de um lado, quer abarcar a diferença, agregando jovens de diferentes áreas do saber e contextos; de outro, tem sua imagem muito vinculada à biologia. Esse limite é importante em se tratando do ambiente dialógico, visto que a abertura para chegada de diferentes pessoas é essencial para a promoção da coexistência da diversidade (SORRENTINO et al., 2013). 
Outros desafios encontrados nos relatos de experiência estão relacionados à dificuldade dos jovens em manterem-se ativos no CJA, como fica claro no relato do Jovem 1: "um dos desafios, foi a permanência dos jovens e interesse dos mesmos em continuar atuando dentro do CJA". Vários jovens sugerem a disponibilidade de tempo, recursos financeiros e a locomoção até o local dos encontros como os principais desafios encontrados para a participação e permanência dentro do CJA. Os motivos são explanados pelo Jovem 7 , ao escrever que "encontrei algumas dificuldades por estar cursando a graduação concomitantemente, por não ter apoio financeiro e o cansaço". 0 Jovem 9 reforça essa dificuldade ao dizer que:

Minhas dificuldades são duas: distância e financeira. De me deslocar de São Vicente até Santos nas atividades de bike debaixo da chuva ou do sol. Além disso, da necessidade financeira, pois estava investindo tempo e recursos para participar e eu poderia estar investindo esse tempo em um trabalho, por conta disso tive que me afastar.

O Jovem 8 e o Jovem 11 além de concordarem sobre estas dificuldades, apresentaram, em seus relatos, a maneira que encontraram para continuar ativos no CJA. O Jovem 8 relatou que realizava horas extras no trabalho para conseguir tempo livre para os encontros e ações do CJA e o Jovem 11 relatou que "a maleabilidade do projeto permitiu com que essas dificuldades não fossem [um] risco à minha presença no coletivo a longo prazo". Ambos os jovens realizaram adaptações às suas rotinas para encaixar os encontros em seu planejamento. Tais falas apresentam elementos que parecem dificultar a manutenção de um ambiente dialógico, apesar dos esforços individuais e coletivos para superação desses desafios (MONTEIRO; SORRENTINO, 2019).

\section{Liderança dialógica}

Para que o Coletivo Jovem Albatroz construa um ambiente onde o diálogo possa emergir, é necessária a presença de um educador que adote a postura de liderança dialógica. Esta se caracteriza por uma série de condutas que fomentam uma relação de confiança entre educador e educando para que juntos consigam transformar a realidade na qual se inserem (FREIRE, 1981).

Visando atingir esse propósito, as formações do CJA buscam estimular o protagonismo juvenil e o pensamento crítico por meio da colaboração na escolha dos temas geradores das ações, seguindo pela práxis, ou seja, os jovens são encorajados a elaborar intervenções educadoras ambientalistas seguidas da reflexão sobre esse processo (PROJETO ALBATROZ, 2020c).

Tal propósito foi enunciado pelo Jovem 13, ao escrever que "o CJA [...] nos proporciona a oportunidade de desenvolver o protagonismo jovem com 
responsabilidade e seriedade, mas sempre mantendo a leveza e o humor nos encontros, gerando um ambiente de empatia e respeito", indicando a intencionalidade do estímulo à prática dialógica pelos educadores responsáveis.

Segundo Freire (1981), é necessário que a liderança adote uma postura de igualdade, ou seja, que o educador seja parte integrante do grupo, estabelecendo e criando um ambiente seguro e de confiança para que o diálogo aconteça.

Nesse sentido, o Jovem 18 identificou, em seu texto, a importância dessa participação ao afirmar que

Achei muito interessante o papel da mediação do curso e das reuniões do CJA, que em nenhum momento se colocou no papel de comandar [...] respeitando e considerando a pluralidade de opiniões, ideias e formas de pensar o mundo, oferecendo aos jovens do coletivo uma autonomia.

Tal fala demonstra a intencionalidade do estabelecimento de uma relação horizontal entre os educadores e os educandos.

O Jovem 1, participante ativo do CJA desde seu início (2015), identificou que o grupo possui autonomia para criar sua própria identidade ao escrever que "conseguimos ao longo dos anos construir um espaço que cada vez mais possui a nossa cara, o nosso olhar e alguma das nossas muitas vontades". 0 Jovem 17 corrobora ao afirmar que a liderança "havia deixado em aberto a possibilidade de cada integrante do coletivo compartilhar dinâmicas com as quais estivessem familiarizados [...] vários integrantes foram levando esses exercícios ao grupo". Essas falas permitem inferir que as pessoas na figura de facilitação adotam a postura da liderança dialógica ao compartilhar a gestão do aprendizado, possibilitando assim o protagonismo juvenil.

\section{Aprendizado do diálogo}

O aprendizado do diálogo foi a categoria adotada para compreender se o processo educador proposto pelos responsáveis pelo CJA oportunizou a vivência e aprendizado do procedimento metodológico sugerido por Monteiro e Sorrentino (2019), que estimula a vivência do diálogo, a compreensão de aspectos da realidade, sobre si e sobre o outro, mudanças de pensamento e ações e a construção de uma nova maneira de agir e pensar com base nas ideias dialogadas.

Os dados obtidos nos relatos de experiência dos jovens dão indicativos do aprendizado do diálogo. O Jovem 16 parece confirmar esse aprendizado ao dizer que "acredito nesse tipo de ensino-aprendizagem: que parte dos seus 
conhecimentos pré-concebidos, os desestabiliza e depois os reconstrói, tudo isso de forma delicada, construtiva e, especialmente no CJA, muito sensível".

O Jovem 9 relata ter aprendido a escutar as opiniões e experiências do restante do grupo, aprendizado que remete ao segundo momento proposto por Monteiro e Sorrentino (2019), o de focar a atenção e realizar uma escuta ativa.

A descrição da codificação, descrita como o momento para a exposição dos pensamentos, sensações, sentimentos e dúvidas por meio de conversas (MONTEIRO; SORRENTINO, 2019), foi evidenciada pelo Jovem 7, ao escrever que "me sentia confortável para compartilhar ideias, opiniões, propostas, sem medo de julgamentos. Aquela ansiedade do princípio ia se esvaindo, no lugar dela vieram os vínculos, o afeto e a forte sensação de pertencimento".

O Jovem 1 apresenta, em seu texto, o aprendizado do último momento proposto, o da (re)admiração, ao escrever que "o CJA contribui para a minha desconstrução diária. Nele, eu revejo os meus pré-conceitos e busco dentro, e fora, daquele espaço me moldar para o melhor". O Jovem 8 também relata ter percebido a (re)admiração que é marcada pela observação das sensações corporais, das emoções e a análise crítica dos próprios pensamentos e ações. Esse momento convida as pessoas a compreenderem a origem dos seus pensamentos, buscando observar se eles ainda fazem sentido ou não para si, para o outro e para o mundo (MONTEIRO; SORRENTINO, 2019).

Outro aspecto importante relatado pelo Jovem 9 é o da emancipação e autonomia para atuar com os aprendizados do diálogo em outras instituições além do CJA, como escreve em seu relato:

Levo o aprendizado dialógico que aplico em diferentes espaços (...) Aprendi sobre Educação Ambiental em teoria e em prática/ações, onde fizemos várias atividades práticas e dinâmicas de grupo. Apliquei a E.A em diferentes espaços e públicos, compreendendo as diferentes áreas do socioambientalismo. Mas também escutar, colocar minhas opiniões de forma respeitosa. Também aprendi sobre Educomunicação, fazer uma reunião, fazer um planejamento e metodologia OCA.

Em complemento, o Jovem 4 disse:

... eu levei do Coletivo Jovem Albatroz muitos aprendizados, experiências profissionais, vivências em grupo e mais do que qualquer coisa aprendi a praticar a escuta ativa e a desenvolver uma comunicação dialógica com intuito de construção e fortalecimento. 
Sendo assim, os indícios apresentados sugerem a ocorrência do aprendizado do diálogo dentro do Coletivo Jovem Albatroz, a partir da promoção de mudanças na forma de pensar e agir dos jovens.

\section{A Contribuição do Diálogo para o Fomento dos Princípios "Jovem Educa Jovem", "Jovem Escolhe Jovem"e "Uma Geração Aprende com a Outra"}

O Estatuto da Juventude é o marco legal que dispõe e garante o direito das juventudes brasileiras à sustentabilidade $e$ ao meio ambiente ecologicamente equilibrado (BRASIL, 2013a).

Para tal, o documento sugere a implementação de EA em todos os níveis de ensino e, também, a participação das juventudes na elaboração das políticas públicas por meio de Coletivos Jovens de Meio Ambiente (CJMA) (BRASIL, 2013b). Entretanto, o manual de CJMA não apresenta uma proposta metodológica a ser seguida.

Portanto, a proposta desta seção é considerar os resultados obtidos neste trabalho e os três princípios orientadores do manual, buscando observar como ambos se complementam.

O ambiente dialógico criado pelo CJA apresenta uma correspondência com o princípio Jovem Educa Jovem (BRASIL, 2005), já que os educadores responsáveis pelos processos de formação buscam compartilhar a gestão do aprendizado com os jovens do Coletivo, de forma que estes protagonizaram a formação de novos jovens, como evidenciado durante o curso de produção audiovisual, em que elaboraram e executaram a formação de novos integrantes do Coletivo (PROJETO ALBATROZ, 2019). Outro aspecto importante é o fato de dois dos três educadores ambientais responsáveis pelo CJA terem sido integrantes do grupo antes de assumir o papel de coordenação e o fizeram dentro da faixa etária jovem, ou seja, enquanto tinham menos de 29 anos de idade. Logo, o cargo de tomada de decisão estava sob o comando de jovens.

Quanto ao princípio Jovem Escolhe Jovem (BRASIL, 2005), vale destacar que, durante as duas últimas formações realizadas pelo Coletivo, os jovens que compuseram a equipe pedagógica dos cursos selecionaram os novos integrantes, aspecto importante para estimular o protagonismo e controle por parte dos jovens do processo em que estão inseridos.

Por fim, a presença da gerente geral do PA, Tatiana Neves e da gerente de Educação Ambiental, Cynthia Ranieri, durante as formações dos jovens, ministrando palestras sobre sua experiência de consolidação do Projeto, pode ser encarada como uma troca entre gerações que ocorre em todas as formações do CJA, fomentando o princípio Uma Geração Aprende com a Outra (BRASIL, 2005).

Tendo em vista o exposto, vale destacar que a implementação dos princípios sugeridos pelo manual (BRASIL, 2005) em conjunto com as práticas dialógicas foram possíveis de serem executadas pelas condições oferecidas 
pelo Projeto Albatroz, como a postura adotada pela coordenadora de Educação Ambiental e a contratação de educadores ambientais para a função, que fizeram parte das formações realizadas pelo grupo. Tais condições fomentam a qualidade da formação, contribuindo para a superação de uma formação tradicional que preza apenas pelo conteúdo e quantidade de participantes.

Esses resultados sugerem que, com o aprendizado do diálogo, os jovens comunicam-se e interagem, mantendo o respeito à essência de cada um e gerando um aprendizado sobre si, sobre o outro e sobre o planeta, criando uma forma de pensar e agir em conjunto (ALVES et al., 2010). Além disso, questionam-se sobre sua relação com o planeta e os outros seres humanos (ANDRADE; LUCA; SORRENTINO, 2012), sendo estimulados a realizar intervenções socioambientais que estabelecem o protagonismo juvenil e o engajamento dos indivíduos (SORRENTINO et al., 2013) participantes do processo.

Com base nos argumentos expostos, pode-se perceber que a Educação Ambiental dialógica realizada pelo CJA possibilitou a criação de um caminho metodológico viável para implementação dos três princípios do Manual de CJMA.

\section{Considerações Finais}

O presente estudo realizou a análise da presença do diálogo ao longo dos diversos processos de formação vivenciados pelo Coletivo Jovem Albatroz, com o objetivo de contribuir para o aprofundamento de conhecimentos sobre o diálogo na formação de jovens ambientalistas.

A partir dos resultados foi possível identificar indícios de estímulo à prática do diálogo, impulsionando seu aprendizado, como: o incentivo ao protagonismo juvenil, ao acolhimento, à segurança, ao pertencimento, ao propósito à uma causa, à troca de múltiplos saberes, o incentivo à expressão, ao respeito, à escuta ativa, à gestão horizontalizada, ao compartilhamento do aprendizado, à igualdade, à autonomia, à identidade, bem como ao aprendizado sobre si, sobre o outro ou sobre algum aspecto da realidade, possibilitando mudanças na forma de agir e pensar dos jovens.

Dessa forma, esta seção, além de explicitar os resultados encontrados na análise, sugere a proposta educadora ambientalista dialógica do CJA como um possível caminho para a implementação e execução em outros Coletivos Jovens de Meio Ambiente que desejam basear sua metodologia nos CJMA.

Além disso, os resultados também apontam desafios importantes para o fomento e a manutenção da prática dialógica, sendo eles: a suposta dificuldade de alguns jovens em aproximar-se do grupo por pensar ser exclusivamente da área biológica e dificuldades financeiras, de deslocamento e de tempo encontradas pelos jovens para permanecerem no CJA. 
A tais desafios, ainda não temos respostas, apenas perguntas a serem respondidas com futuras pesquisas: como atrair jovens de diferentes áreas do conhecimento para um coletivo jovem de meio ambiente? Qual(is) temática(s) problematizadora(s) pode $(\mathrm{m})$ atrair e engajar esses jovens tão distintos? Como um coletivo jovem de meio ambiente pode desenvolver captação de recursos para suprir suas necessidades financeiras? Qual a melhor maneira de distribuir os rendimentos para suprir as dificuldades financeiras? Um coletivo pode realizar a prestação de serviços como uma maneira de arrecadar finanças?

Sendo assim, sugere-se a realização de mais pesquisas sobre a interface diálogo, juventude e meio ambiente com o propósito de aprofundar a compreensão a respeito dos benefícios e desafios da implementação da prática do diálogo em processos educadores com juventudes que almejam o fomento da transição para sociedades sustentáveis.

\section{Referências}

ALVES, D. M. G., ANDRADE, D. F., BARBOSA, C. R., BIASOLI, S. A., BIDINOTO, V. M., BRIANEZI, T., CARRARA, M., COATI, A. P., COSTA PINTO, A. B., FERREIRA, L. E. C., LUCA, A. Q., MACHADO, J. T., NAVARRO, S.d M., PORTUGAL, S., RAIMO, A. A., SACCONI, L. V., SIM, E. F.C., SORRENTINO, M. Em busca da sustentabilidade educadora ambientalista. In: AmbientalMENTEsustentable, 2010, ano V, vol. I, núm. 9-10, p. 7-35.

ANDRADE, D. F. O lugar do diálogo nas políticas públicas de Educação Ambiental. Tese (Doutorado em Ciência Ambiental) - Universidade de São Paulo, São Paulo, 2013.

ANDRADE, D. F., LUCA, A. Q., SORRENTINO, M. O diálogo em processos de políticas públicas de Educação Ambiental no Brasil. Educação Social, Campinas, v. 33, n. 119, p. 613-630, abr-jun 2012.

AVANZI, M. R. Tecido a muitas mãos: experienciando diálogos na pesquisa em Educação Ambiental. Tese (Doutorado em Educação) - Universidade de São Paulo, São Paulo, 2005.

BRASIL. Coletivos Jovens de Meio Ambiente: Manual Orientador. Brasília, DF: Órgão Gestor da PNEA, 2005.

BRASIL. Lei no 12.852, de 5 de agosto de 2013. Estatuto da Juventude. Brasília: Diário Oficial da União, 2013a.

BRASIL. Programa Nacional de Juventude e Meio Ambiente. Brasília: Ministério do Meio Ambiente, 2013b. Disponível em: <http://www.mma.gov.br/ educacao-ambiental/formacao-de-educadores $>$. Acesso em 12 ago 2020. 
BRASIL. ProNEA - Programa Nacional de Educação Ambiental. Ministério do Meio Ambiente, Departamento de Educação Ambiental; Ministério da Educação, Coordenação Geral de Educação Ambiental. - 5 ed $^{\mathrm{a}}$ - Brasília: MMA, DF, 2018. Disponível em: $<$ https://www.infraestruturameioambiente.sp.gov.br/educacaoambiental/prateleir a-ambiental/programa-nacional-de-educacao-ambiental-pronea-5a-edicao/>. Acesso em: 16 ago 2020.

FÓRUM GLOBAL DAS ONGs. Tratado de Educação Ambiental para Sociedades Sustentáveis e Responsabilidade Global. Rio de Janeiro: 1992. Disponível em: $<$ http://portal.mec.gov.br/secad/arquivos/pdf/educacaoambiental/tratado.pdf>. Acesso em: 25 mar. 2014.

FREIRE, P. Pedagogia do Oprimido. 10 $10^{\mathrm{a}}$ ed. Rio de Janeiro: Paz e Terra, 1981.

JACOBI, P. R.; MONTEIRO, R. A. A.; SOUZA, D. T. P. Caminhos para uma nova ética em tempos pós COVID-19: o desafio de ampliar diálogos e fortalecer aprendizagem social In: SOBRINHO, L. L. P.; CALGARO, C.; ROCHA, L. S. (Org.) COVID-19: direitos humanos e educação. Itajaí: UNIVALI, 2020.

LOPES, T. C., SANTÀNA, B. C. da C., CARDOSO, L. G., RODRIGUES, M. de S., ALMEIDA, M. M., CARDOSO, R. S., RIBEIRO, V. V., SARACHO, Y. D., \& MONTEIRO, R. de A. A. COVID-19 e questões estruturais: a transformação por meio do diálogo e da colaboração. Revista Brasileira De Educação Ambiental, v.15, n.4, pp. 440-455, 2020.

LUCA, A. Q.; ANDRADE, D. F. O 'diálogo' como objeto de pesquisa na Educação Ambiental. In: GUNTZEL-RISSATO, C. et al. Educação Ambiental e políticas públicas: conceitos, fundamentos e vivências. Curitiba: Appris, 2013, p. 119-129.

LUDKE, M; ANDRÉ, M. E. D. A. Pesquisa em Educação: Abordagens Qualitativas. São Paulo: EPU, 1986.

MONTEIRO, R. A. A. ; SANT'ANA, B. C. C. ; FONSECA, A. C. ; OLMOS, C. ; FALASCO, C. F. ; SILVA, C. P. ; KOCSSIS, E. ; RAMOS, F. ; GRAVANICH, G. ; SANTOS, G. D. ; CARVALHO, I. B. ; NETO, J. P. ; CARDOSO, L. G. ; SILVA, L. A. R. ; SILVA, L. F. ; SCARÍMBOLO, L. G. ; RODRIGUES, M. S. ; ROEDEL, M. D. ; CARDOSO, R. S. ; OLIVEIRA, S. A. ; RANIERI, C. A Temática dos Resíduos Sólidos dentro dos Processos de Educação Ambiental desenvolvidos pelo Projeto Albatroz. UNISANTA BIOSCIENCE , v. 7, p. 1-8, 2018.

MONTEIRO, R. A. A.; SORRENTINO, M. O Diálogo na Educação Ambiental: uma Síntese A Partir de Martin Buber, David Bohm, William Isaacs e Paulo Freire. Pesquisa em Educação Ambiental, v.14, n.1, 2019. 
MONTEIRO, R. A. A.; RIBEIRO, V. V.; Diálogo e formação de jovens ambientalistas: uma experiência do Coletivo Jovem Albatroz. In: MONTEIRO, R. A. A.; SORRENTINO, M.; JACOBI, P. R. Diálogo e Transição Educadora para Sociedades Sustentáveis. São Paulo: IEE-USP : Editora Na Raiz, 2020.

OCA. O "Método Oca" de Educação Ambiental: fundamentos e estrutural incremental. Ambiente \& Educação, v. 21, n. 1, p. 75-93, 2016.

ÓRGÃO GESTOR DA PNEA. Programa nacional de formação de educadoras(es) ambientais: por um Brasil educado e educando ambientalmente para a sustentabilidade. Brasília, DF, 2006.

PROJETO ALBATROZ. Relatório CJA Final - Evidência de realização das ações. 2015.

PROJETO ALBATROZ. Relatório CJA - Evidência de realização das ações. 2016.

PROJETO ALBATROZ. Relatório 5 Quadrimestre - Evidência de realização das ações: Questão 5C. 2019.

PROJETO ALBATROZ. História. 2020a Disponível em: $<$ https://projetoalbatroz.org.br/sobre-o-projeto-albatroz/quem-somos/historia>.

Acesso em: 08 mai 2020.

PROJETO ALBATROZ. Rede Biomar. 2020b. Disponível em: $<$ https://projetoalbatroz.org.br/sobre-o-projeto-albatroz/quem-somos/redebiomar>. Acesso em: 27 abr. 2020.

PROJETO ALBATROZ. Jovem Albatroz. 2020c. Disponível em: $<$ https://projetoalbatroz.org.br/educacao-ambiental/coletivo-jovem-albatroz>. Acesso em: 29 jan. 2020.

REDE BIOMAR. Relatório Rede Biomar - 10 anos. 2016 - Outras evidências de realização das ações. 2016.

ROESE, M. W. V. Educação Ambiental dialógico-crítica e a conservação da biodiversidade no entorno de áreas protegidas. Tese (Doutorado em Ecologia e Recursos Naturais) - Universidade Federal de São Carlos, São Carlos, 2014.

SILVA, L. P. Conflitos socioambientais: uma proposta de investigação-ação à luz da Educação Ambiental dialógico-problematizadora. Tese (Doutorado em Ciências Ambientais) - Universidade Federal de Goiás, Goiânia, 2016.

SORRENTINO, M. et al. Educação Ambiental como Política Pública. Educação e Pesquisa, 2005, v. 31, n. 2, p. 285-299.

SORRENTINO, M. et al. Comunidade, identidade, diálogo, potência de agir e felicidade: fundamentos para Educação Ambiental. In: GUNTZEL-RISSATO, C. et al. (Org.) Educação Ambiental e políticas públicas: conceitos, fundamentos e vivências. Curitiba: Appris, 2013, p. 36-41. 